Article

\title{
The Fracture Behavior and Thermal Stability of Commercially Pure Nickel Sheets Processed by Constrained Groove Pressing
}

\author{
Zongshen Wang ${ }^{1, *} \mathbb{D}$, Yanjin Guan ${ }^{2},{\operatorname{Lin~} \mathrm{Li}^{1} \text { and Lihua Zhu }}^{1}$ \\ 1 School of Mechanical Engineering, Shandong University of Technology, Zibo 255000, China; \\ 17865916509@163.com (L.L.); zhulihua@sdut.edu.cn (L.Z.) \\ 2 School of Materials Science and Engineering, Shandong University, Jinan 250061, China; \\ guan_yanjin@sdu.edu.cn \\ * Correspondence: wangzsh@sdut.edu.cn; Tel.: +86-1575-331-9868
}

Received: 21 August 2019; Accepted: 24 September 2019; Published: 26 September 2019

\begin{abstract}
Constrained groove pressing (CGP) is one of the most promising severe plastic deformation (SPD) techniques suitable for producing ultra-fine grained (UFG) sheet or plane metallic materials with unique physical, chemical, and mechanical properties. However, the heavily deformed sheets are usually with high strength but low ductility due to work hardening and micro-cracking, and the UFG microstructure and high strength are unstable especially when exposed to high temperatures. Thus, in this work, CGP was conducted on commercially pure nickel sheets and, firstly, the fracture mechanism of the processed sheets was examined. Then, the annealing behavior of CGP nickel sheets was investigated in detail to explore their thermal stability and improve their ductility. The results showed that significant grain refinement and strength improvement of the nickel sheets were achieved with great loss of ductility. The fracture surface morphology of the sheet sample exhibited typical characteristics of fatigue fracture, and inhomogeneous strain distribution and work hardening determined the micro-crack initiation position and propagation direction. The CGP sheets by one and two passes showed high thermal stability up to 650 and $600^{\circ} \mathrm{C}$, respectively, owing to different stored internal stresses and accumulated energy. In both cases, obvious recovery of elongation to failure from $12.7 \%$ and $10.6 \%$ to $29.3 \%$ and $27.3 \%$ were achieved by CGP with post-deformation annealing treatment, respectively, with acceptable drop of strength.
\end{abstract}

Keywords: constrained groove pressing; severe plastic deformation; nickel sheets; fracture; annealing behavior; thermal stability

\section{Introduction}

Due to exceptional physical, mechanical, and functional properties, ultra-fine grained (UFG) materials have gained great interest subjects in recent years [1]. Severe plastic deformation (SPD) has been widely accepted as a straightforward and effective way of producing bulk UFG materials [2]. Constrained groove pressing (CGP), originally proposed by Shin et al., is one of the versatile SPD methods suitable for fabrication of UFG metallic sheets [3,4]. During the CGP process, as shown in Figure 1, a set of asymmetrically groove dies and a set of flat dies are employed to perform alternate groove pressing and flattening on sheet metals. Based on the die constraint, the asymmetry of groove dies and the $180^{\circ}$ rotation of sheet sample around its normal direction (ND), theoretically, pure shear deformation will be imposed to the whole sheet sample without obvious changes in its dimensions. Thus, by repeating this process, a large amount of plastic strain could be homogeneously accumulated into the materials and UFG structures as well as enhanced properties are expected to be obtained [5]. 
Until now, CGP has been successfully used for grain refinement and property improvement of various pure metals and alloys [4].

T - Groove width, $\theta$ - Groove angle

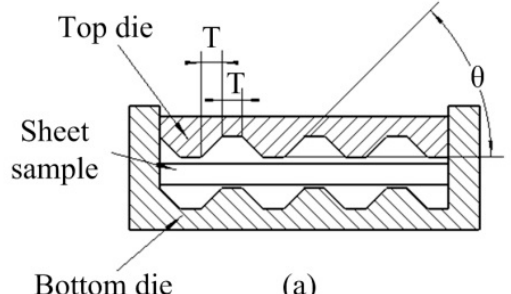

Bottom die

(a)
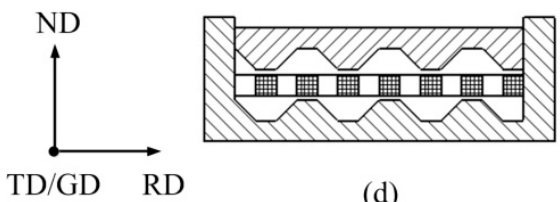

(d)

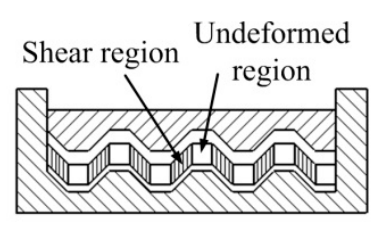

(b)

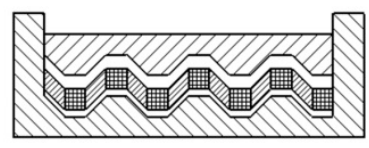

(e)

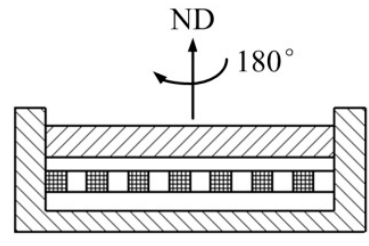

(c)

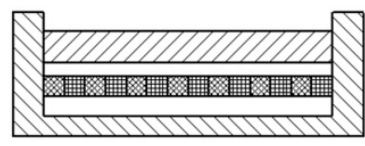

(f)

Figure 1. Schematic of the constrained groove pressing (CGP) process: (a) Preparation; (b) press 1 ; (c) flat 1; (d) sample rotation; (e) press 2; (f) flat 2. Reproduced from [5], with permission from Elsevier, 2019.

However, the severely deformed materials fabricated by SPD usually have fine grains with high lattice distortion and internal stresses [6]. The strain-induced fine grain boundaries migrate easily when exposed to high temperatures, resulting in rapid grain growth. Thus, the thermal stability of UFG structures and improved properties introduced by SPD is a significant concern in its technical application. In addition, SPD materials usually have high strength but low ultimate tensile strain. In this regard, it is important to study the annealing behavior of SPD materials with the objective of exploring their thermal stability and improving the ductility and toughness with minimized loss of strength [7-9]. So far, several investigations about the influence of heat treatment on CGP materials have been reported. Rafizadeh et al. found that intermediate and post-deformation annealing up to $300{ }^{\circ} \mathrm{C}$ did not significantly change the mechanical properties of CGP copper sheets, and microstructure after post-deformation annealing at elevated temperatures experienced abnormal grain growth [10]. Khodabakhshi and Kazeminezhad investigated the annealing responses of low carbon steel sheets after CGP [11]. It was revealed that annealing could effectively improve the elongation to failure of CGP sheets with preserving the hardness and strength, and $400{ }^{\circ} \mathrm{C}$ was recognized as an optimum annealing temperature to increase strength, elongation, and hardness homogeneity of the sheets. The microstructure stability of AZ31 magnesium alloy sheets after three passes of CGP was studied by Fong et al. through isothermal annealing at temperatures from 200 to $350{ }^{\circ} \mathrm{C}$ and for different times [6]. Abnormal grain growth associated with increased non-basal grains at the expense of basal grains occurred at $350^{\circ} \mathrm{C}$. Jandaghi et al. carried out detailed analysis about the influence of cold-rolling and post-deformation annealing on microstructure evolution and mechanical properties of CGP Al-Mn-Si alloy sheets $[8,12-14]$. The alloy sheets exhibited thermal stability up to about $250^{\circ} \mathrm{C}$ and this critical temperature was reduced to around $150^{\circ} \mathrm{C}$ by cold rolling. In their work, post-rolling of two-pass CGP sheets by the strain of 0.8 and subsequent annealing at $350{ }^{\circ} \mathrm{C}$ was found to be an optimum process route for the achievement of superior tensile properties.

Nickel is a suitable model material for investigating microstructure evolution during SPD owing to its good plasticity and relatively high melting temperature and stacking fault energy [15]. Few literatures about CGP of nickel sheets have been published. Satheesh Kumar and Raghu investigated the mechanical properties, especially the tensile behavior and strain hardening characteristics, and microstructure evolution of commercially pure nickel sheets during CGP [16,17]. In initial passes of CGP, noticeable drop in ductility of the sheets associated with reduced strain hardening 
ability was observed while ductility recovery occurred during later passes. Influences of die structure on CGP of nickel sheets were studied by the authors via experimental and numerical methods [18]. The highest strength and hardness but relatively low elongation to failure for the sheets with a thickness of $2 \mathrm{~mm}$ was obtained by a two-pass CGP with a groove width of $2 \mathrm{~mm}$ and a groove angle of $45^{\circ}$. Moreover, it was found that bending instead of pure shear induced by a higher groove angle or ratio of groove width to sheet thickness would result in micro-cracks at the sheet surface due to work hardening and stress concentration. However, there are no reports regarding heat treatment of CGP nickel sheets. Thus, as a further study on CGP of commercially pure nickel sheets, fracture characteristics of the sheets were explored in this work, and annealing behavior of microstructure and properties of CGP nickel sheets were investigated in detail, in order to examine their thermal stability and improve the ductility.

\section{Materials and Methods}

Cold-rolled commercially pure nickel sheets with dimensions of $100 \mathrm{~mm} \times 66 \mathrm{~mm} \times 2 \mathrm{~mm}$ were fully annealed at $750{ }^{\circ} \mathrm{C}$ for $4 \mathrm{~h}$ before CGP. CGP was conducted on a $5000 \mathrm{kN}$ computer-controlled electro-hydraulic servo compression testing machine operating at a constant press speed of $5 \mathrm{~mm} / \mathrm{min}$. Three combinations of groove width $(\mathrm{T})$ and groove angle $(\theta)$ were chosen and defined as Scheme 1 $\left(\mathrm{T}=2 \mathrm{~mm}, \theta=37^{\circ}\right)$, Scheme $2\left(\mathrm{~T}=2 \mathrm{~mm}, \theta=45^{\circ}\right)$, and Scheme $3\left(\mathrm{~T}=3 \mathrm{~mm}, \theta=45^{\circ}\right)$. The rolling direction (RD) of the sheet sample was perpendicular to the groove direction (GD) of groove dies when pressing, as illustrated in Figure 1. Detailed procedures can be found in our previous work [18]. Then, the CGP nickel sheets were post-annealed at temperatures from 200 to $800{ }^{\circ} \mathrm{C}$ with an interval of $50^{\circ} \mathrm{C}$ for $5,15,30$ and $60 \mathrm{~min}$ in an SX2-12 resistance-heated furnace and air cooled to room temperature (RT) to explore their annealing behavior.

Optical microscope and TEM were employed to examine microstructure evolution of the materials during CGP and subsequent annealing. To determine the average grain size using optical micrographs, at least three fields of views were investigated. TEM specimens were prepared by conventionally mechanical polishing and ion thinning, and bright field imaging and selected-area electron diffraction (SAED) were performed on a JEM 2100 high resolution TEM operating at $200 \mathrm{kV}$. The surface morphology of the fractured sheet sample was observed by an SU-70 field emission SEM.

Tensile tests and micro-hardness measurements were used to investigate the mechanical properties of the sheets. Tensile specimens with gage length of $25 \mathrm{~mm}$, width of $6 \mathrm{~mm}$ and thickness of $2 \mathrm{~mm}$ were directly machined from the sheet sample according to the ASTM E8Mstandard. The gage length was aligned along the RD of the sheet sample. RT tensile tests were carried out on an INSTRON5569 universal materials testing machine at a constant cross head speed of $3 \mathrm{~mm} / \mathrm{min}$, and three specimens were tested for each condition. Vickers micro-hardness was measured at ND-RD cross section of the sheet sample after mechanical surface grinding and polishing with a load of $500 \mathrm{gf}$ and a loading period of $10 \mathrm{~s}$, and more than ten measurements were taken for an average.

\section{Results and Discussion}

\subsection{Mechanical Properties and Fracture Behavior of Nickel Sheets During CGP}

Mechanical properties of commercially pure nickel sheets processed by CGP with different die structures are summarized in Table 1. Significant enhancement of strength and hardness accompanied by great decrease of elongation to failure was evident for all processed sheets. Relatively acceptable mechanical properties were obtained after pass 2 in Scheme 2, and the yield strength (YS) and ultimate tensile strength (UTS) were 476.3 and $532.3 \mathrm{MPa}$, respectively, the hardness was $218.9 \mathrm{HV}$ while the elongation to failure was only $10.6 \%$ [18]. It has been well known that grain refinement and work hardening contributed to the initial strengthening of the materials while flow softening and micro-cracks caused the subsequent softening [19]. Usually, the effect of micro-cracks on tensile properties of CGP sheets was more remarkable than that of flow softening [20]. Thus, in order to 
prevent the crack initiation and propagation and improve the ductility, it is of great importance to investigate the fracture behavior of CGP sheets.

Table 1. Mechanical properties of nickel sheets before and after CGP [18].

\begin{tabular}{|c|c|c|c|c|c|}
\hline \multicolumn{2}{|c|}{ Mechanical Properties } & YS/MPa & UTS/MPa & $\begin{array}{l}\text { Elongation to } \\
\text { Failure/\% }\end{array}$ & Hardness/HV \\
\hline \multicolumn{2}{|c|}{ As-annealed } & $79.6 \pm 3.4$ & $398.1 \pm 2.4$ & $51.0 \pm 2.3$ & $90.0 \pm 3.7$ \\
\hline \multirow{5}{*}{$\begin{array}{c}\text { Scheme } 1 \\
\left(\mathrm{~T}=2 \mathrm{~mm}, \theta=37^{\circ}\right)\end{array}$} & Pass 1 & $407.9 \pm 1.3$ & $475.1 \pm 3.0$ & $16.1 \pm 0.4$ & $185.4 \pm 8.0$ \\
\hline & Pass 2 & $428.6 \pm 19.2$ & $487.4 \pm 16.8$ & $14.2 \pm 3.8$ & $201.7 \pm 8.3$ \\
\hline & Pass 3 & $439.7 \pm 30.2$ & $497.6 \pm 13.4$ & $13.1 \pm 4.3$ & $206.3 \pm 12.0$ \\
\hline & Pass 4 & $427.8 \pm 18.1$ & $463.2 \pm 5.0$ & $7.7 \pm 6.1$ & $208.9 \pm 11.6$ \\
\hline & Pass 5 & $406.9 \pm 7.7$ & $423.9 \pm 11.9$ & $3.4 \pm 0.6$ & $214.8 \pm 11.5$ \\
\hline \multirow{4}{*}{$\begin{array}{c}\text { Scheme } 2 \\
\left(\mathrm{~T}=2 \mathrm{~mm}, \theta=45^{\circ}\right)\end{array}$} & Pass 1 & $458.5 \pm 7.9$ & $499.1 \pm 1.5$ & $12.7 \pm 5.7$ & $213.1 \pm 5.9$ \\
\hline & Pass 2 & $476.3 \pm 3.2$ & $532.3 \pm 7.9$ & $10.6 \pm 3.3$ & $218.9 \pm 17.6$ \\
\hline & Pass 3 & $454.5 \pm 18.1$ & $488.9 \pm 12.0$ & $4.6 \pm 0.8$ & $219.5 \pm 10.9$ \\
\hline & Pass 4 & $393.1 \pm 0.2$ & $416.2 \pm 32.1$ & $0.2 \pm 0.0$ & $222.5 \pm 13.0$ \\
\hline \multirow{3}{*}{$\begin{array}{c}\text { Scheme } 3 \\
\left(\mathrm{~T}=3 \mathrm{~mm}, \theta=45^{\circ}\right)\end{array}$} & Pass 1 & $359.5 \pm 6.1$ & $425.9 \pm 7.8$ & $5.2 \pm 1.9$ & $198.1 \pm 8.8$ \\
\hline & Pass 2 & $384.7 \pm 11.5$ & $413.4 \pm 3.0$ & $3.4 \pm 1.6$ & $203.2 \pm 15.1$ \\
\hline & Pass 3 & $275.6 \pm 10.9$ & $283.6 \pm 12.2$ & $2.8 \pm 0.2$ & $212.8 \pm 10.5$ \\
\hline
\end{tabular}

Obviously in Table 1, the earliest fracture of nickel sheets occurred after pass 3 in Scheme 3. To further explore the fracture mechanism of CGP sheets, SEM observation was conducted on the fracture surface of groove pressed sample, as illustrated in Figure 2. The fracture morphology covering the whole thickness section is shown in Figure 3a. Obviously, it could be divided into three regions by the dashed line indicated as A, B, and C in Figure $3 b-d$, respectively. Accordingly, the fracture surface exhibited three distinctive fatigue regimes: (a) Initiation, (b) propagation and, (c) final failure [21]. Figure $3 b, c$ depicted the initiation and propagation of fatigue crack from the sample surface close to the groove corners. Fatigue striations suggesting the occurrence of cyclic deformation in the materials were observed to be perpendicular to the direction of crack propagation in Figure 3c. Finally, as shown in Figure 3d, numerous small and shallow tear dimples were evident in the final failure region, indicating ductile fracture but decreased ductility of the materials. Thus, from this point, typical characteristics of fatigue fracture were ascertained for CGP sheets especially when the deformation mode transformed from pure shear to bending, owing to improper die structure [18], lubrication [22], or constraint [23]. Another reason for the fatigue fracture was the simple deformation field of traditional CGP procedure contributing to the cyclic deformation of the materials around the groove corners [24]. Therefore, changing straining/deformation paths could provide the chance of obtaining CGP sheets free of fatigue fracture [9].

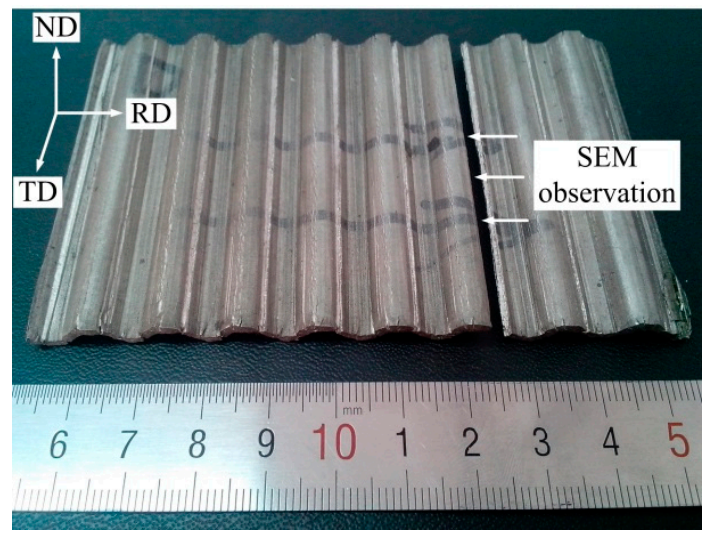

Figure 2. Fractured sheet sample after pass 3 in Scheme 3 showing location for SEM observation. 


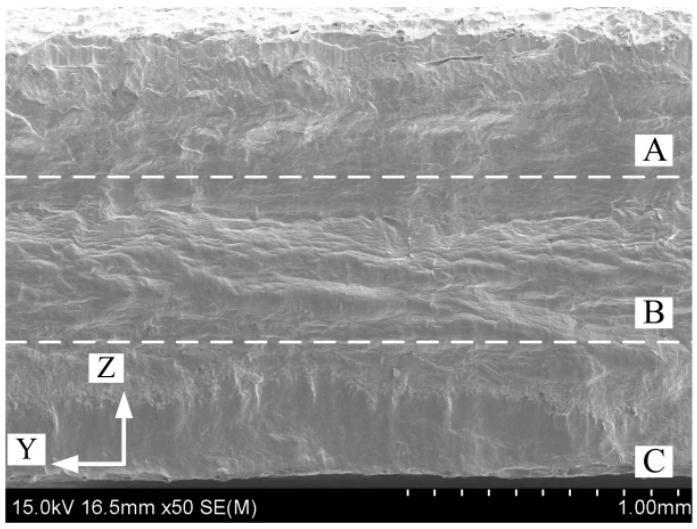

(a)

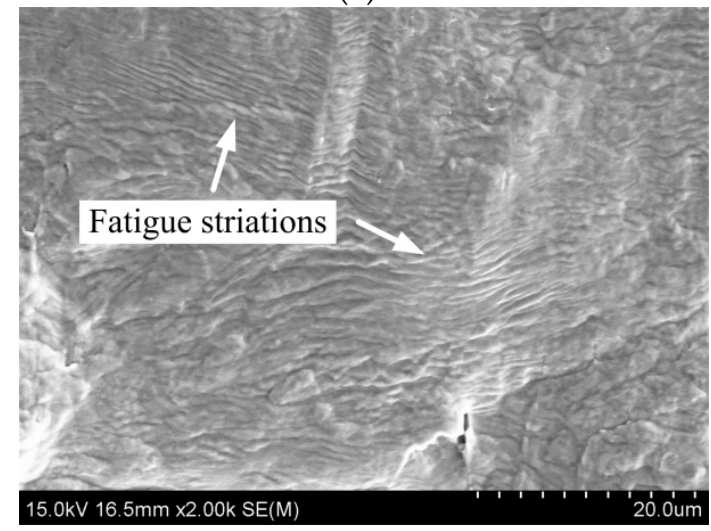

(c)

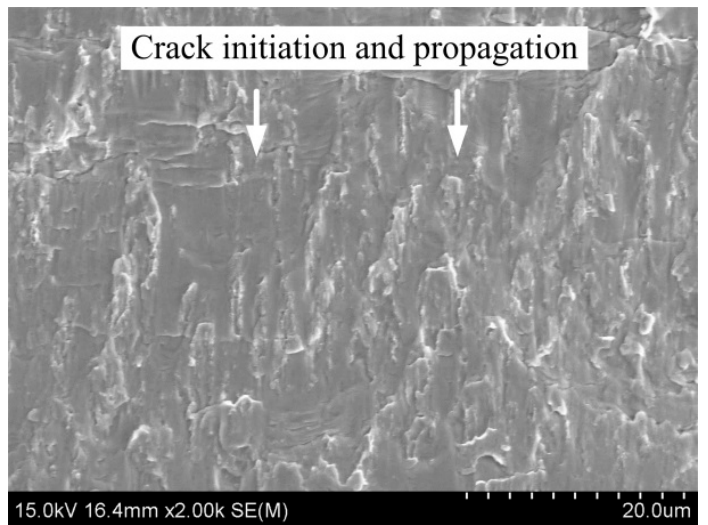

(b)

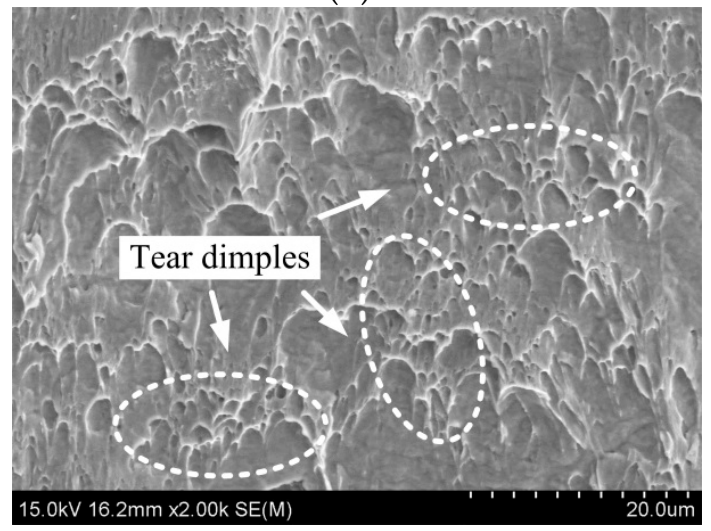

(d)

Figure 3. SEM observation of fracture surface morphology for CGP nickel sheets after pass 3 in Scheme 3: (a) Whole section; (b) region A; (c) region B; (d) region C.

It has been revealed that the change of deformation mode as well as the localized plastic deformation during CGP led to deformation marks appearing at the sheet surface and serving as sites of stress concentration [18]. Fatigue cracks thus preferentially initiated from the deformation marks and propagated through the grains. In other words, it was the deformation inhomogeneity and work hardening that determined the micro-crack initiation position and propagation direction. Practically, there were interface regions between shear regions and undeformed regions, as illustrated in Figure 1b, which caused inhomogeneous strain distribution [25]. Micro-shear bands developed due to inhomogeneous strain distribution were observed in the deformed structure, as shown in Figure 4. The shear-band formed under surface micro-crack facilitated crack propagation between the less and more work-hardened regions corresponding to microstructures basically including equiaxed and elongated grains, respectively, indicated by the white arrow [26]. 


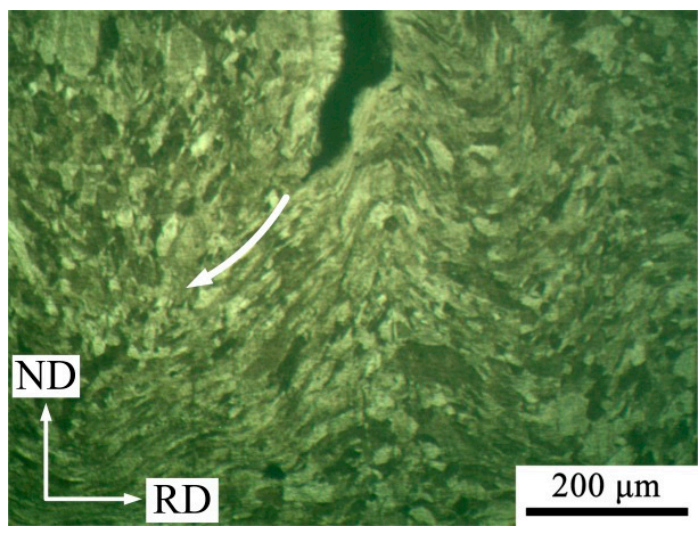

Figure 4. Micro-crack propagation of CGP nickel sheets after pass 3 in Scheme 3.

\subsection{Annealing Behavior of CGP Nickel Sheets}

Figure 5 presents the microstructure evolution of nickel sheets during CGP in Scheme 2. As shown in Figure 5a, the fully annealed sheets at ND-RD cross section mainly consisted of equiaxed grains and a small number of annealing twins. The average grain size estimated by line intercept method was about $28.5 \mu \mathrm{m}$. It was greatly refined to $20.9 \mu \mathrm{m}$ after pass 1 , contributing to the remarkable enhancement of strength and hardness discussed above, and grain refinement was not significant during the following passes, as shown in Figure 5b-e. Finally, the grain size was decreased to about $15.5 \mu \mathrm{m}$ after pass 4 , and TEM micrograph depicted subgrains sized around $0.5 \mu \mathrm{m}$ with high misorientation angles indicated by the corresponding SAED patterns, as shown in Figure $5 \mathrm{f}$. Nevertheless, the UFG structure fabricated by CGP may not be stable, especially when exposed to high temperatures. Meanwhile, although relatively high strength and hardness were achieved for the nickel sheets, a great loss of elongation to failure could not be avoided, as listed in Table 1. Thus, post-deformation annealing was conducted on CGP nickel sheets after one and two passes in Scheme 2 in order to examine thermal stability of the deformed structure and improve their ductility.
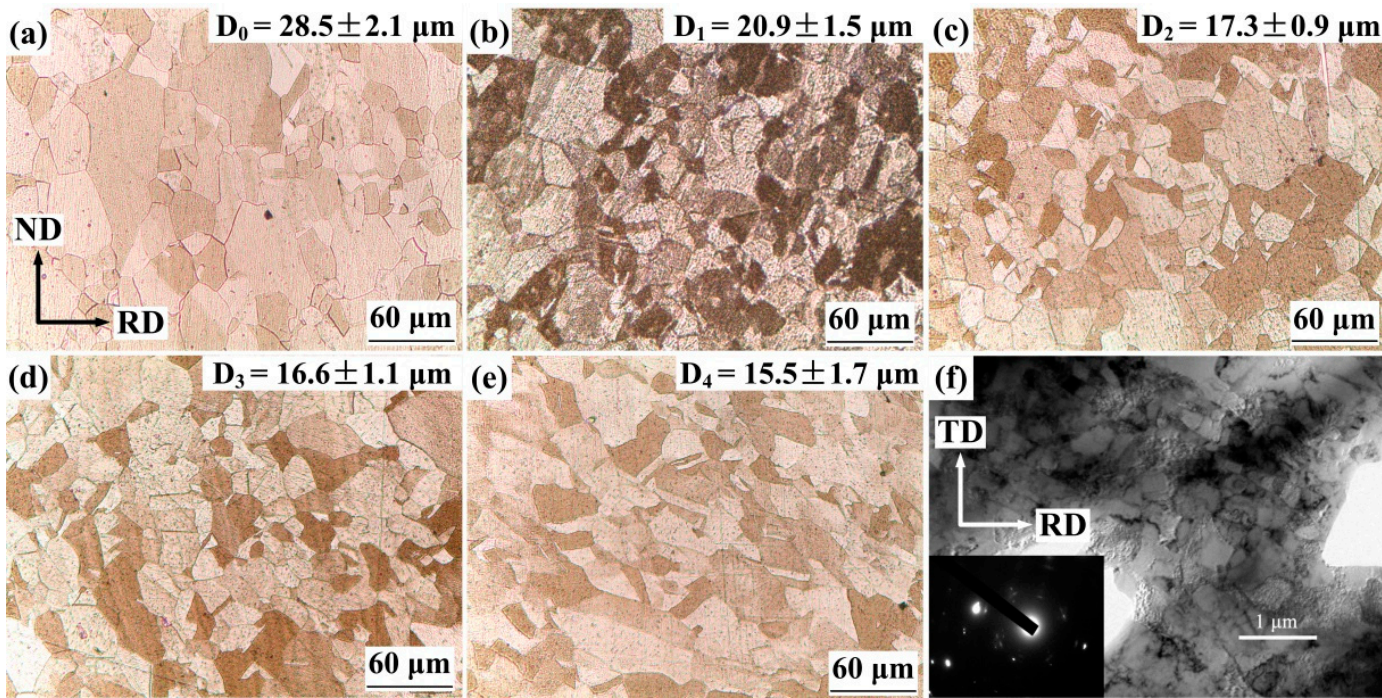

Figure 5. Microstructure evolution of nickel sheets during CGP in Scheme 2: (a) As-annealed; (b) pass 1 ; (c) pass 2; (d) pass 3; (e) pass 4; (f) pass 4 (TEM micrograph with selected-area electron diffraction (SAED) patterns). $\mathrm{D}_{0}, \mathrm{D}_{1}, \mathrm{D}_{2}, \mathrm{D}_{3}$ and $\mathrm{D}_{4}$ indicate the estimated grain sizes.

Figures 6 and 7 present the optical microstructure of CGP nickel sheets after pass 1 and pass 2 with subsequent annealing at different temperatures and time, respectively. The microstructures 
annealed at temperatures below $600{ }^{\circ} \mathrm{C}$ had little difference from each other and hence only those at 200 and $400{ }^{\circ} \mathrm{C}$ were given here. Corresponding grain sizes estimated by line intercept method were illustrated in Figure 8a,b. As shown in Figures 6 and 8a, for CGP nickel sheets after pass 1, the variations of both grain size and micro-hardness against annealing temperature experienced three stages. At first, insignificant increase of grain size was observed when annealed at temperatures below $650^{\circ} \mathrm{C}$, and shear deformation characteristics of microstructure gradually disappeared with the increase of temperature. Usually, elongated grains/subgrains formed after CGP due to its deformation mode and inhomogeneous strain distribution especially during the last passes, as shown in Figure 5e,f. Micro shear-bands could also be observed in the microstructure, as presented in Figure 4 . When annealing, an aspect ratio enhancement with increasing the temperature occurred owing to strain induced grain boundary migration phenomenon. This suggested that annealing in this range facilitated the restoration phenomenon by releasing the residual stress and stored energy of the deformed materials [12]. Partial recrystallization occurred at the same time when annealed for no less than $15 \mathrm{~min}$ and the microstructure was similar to the initial state (before CGP). However, as for the micro-hardness, it experienced slight decrease below $600{ }^{\circ} \mathrm{C}$ while at $650{ }^{\circ} \mathrm{C}$ the effect of annealing time was more remarkable, and the micro-hardness decreased obviously with increasing the annealing time. Then, annealing at a higher temperature of $700{ }^{\circ} \mathrm{C}$ resulted into great increase of grain size accompanied by dramatic decrease of micro-hardness, indicating the completion of recrystallization and grain growth. Finally, continuing slight grain growth was evident at temperatures higher than $700{ }^{\circ} \mathrm{C}$ while negligible recovery of micro-hardness was observed, which might be recognized as annealing strengthening [11]. In addition, generally, the influence of annealing temperature on the microstructure of CGP nickel sheets was more remarkable than that of annealing time in the range from 5 to $60 \mathrm{~min}$.

For CGP nickel sheets after pass 2, similar variation trends of microstructure and micro-hardness against annealing temperature and time are displayed in Figures 7 and $8 \mathrm{~b}$. However, due to doubled effective plastic strain induced by two CGP passes, several differences could be figured out from Figure 8. Firstly, the dramatic decrease of micro-hardness as well as increase of grain size occurred at $600{ }^{\circ} \mathrm{C}$, instead of $650{ }^{\circ} \mathrm{C}$ for pass 1 , demonstrating lower thermal stability caused by higher strain. This suggested that the internal elastic stresses and accumulated energy increased with CGP pass number, leading to higher driving force of recovery and recrystallization [15]. Similar results were obtained in materials processed by other SPD methods [15,27]. Secondly, it was found that imposing higher strain by more passes obviously facilitated the microstructure refinement after post-deformation annealing treatment. For example, the largest grain size of about $50 \mu \mathrm{m}$ for the materials after pass 1 was obtained when annealed at $800^{\circ} \mathrm{C}$ for $1 \mathrm{~h}$ while that for pass 2 was only around $40 \mu \mathrm{m}$. This could be interpreted by the higher stored energy and dislocation density which favored the grain nucleation procedure through providing the necessary driving force and preferred nucleation sites [9]. Thirdly, the effect of annealing time on variation of micro-hardness was more insignificant when heating materials deformed by more passes especially at higher temperatures. For instance, as shown in Figure 8a, longer annealing time resulted into lower micro-hardness, which was more remarkable at temperatures above $600{ }^{\circ} \mathrm{C}$. Interestingly, slight recovery of micro-hardness was also observed in Figure 8 a when annealing at $800{ }^{\circ} \mathrm{C}$ for no less than $15 \mathrm{~min}$. This demonstrated that annealing strengthening caused by the rearrangement of dislocation during restoration occurred evidently for the materials after pass 1 , and a short annealing time like 5 min may not induce this phenomenon $[11,28]$. 

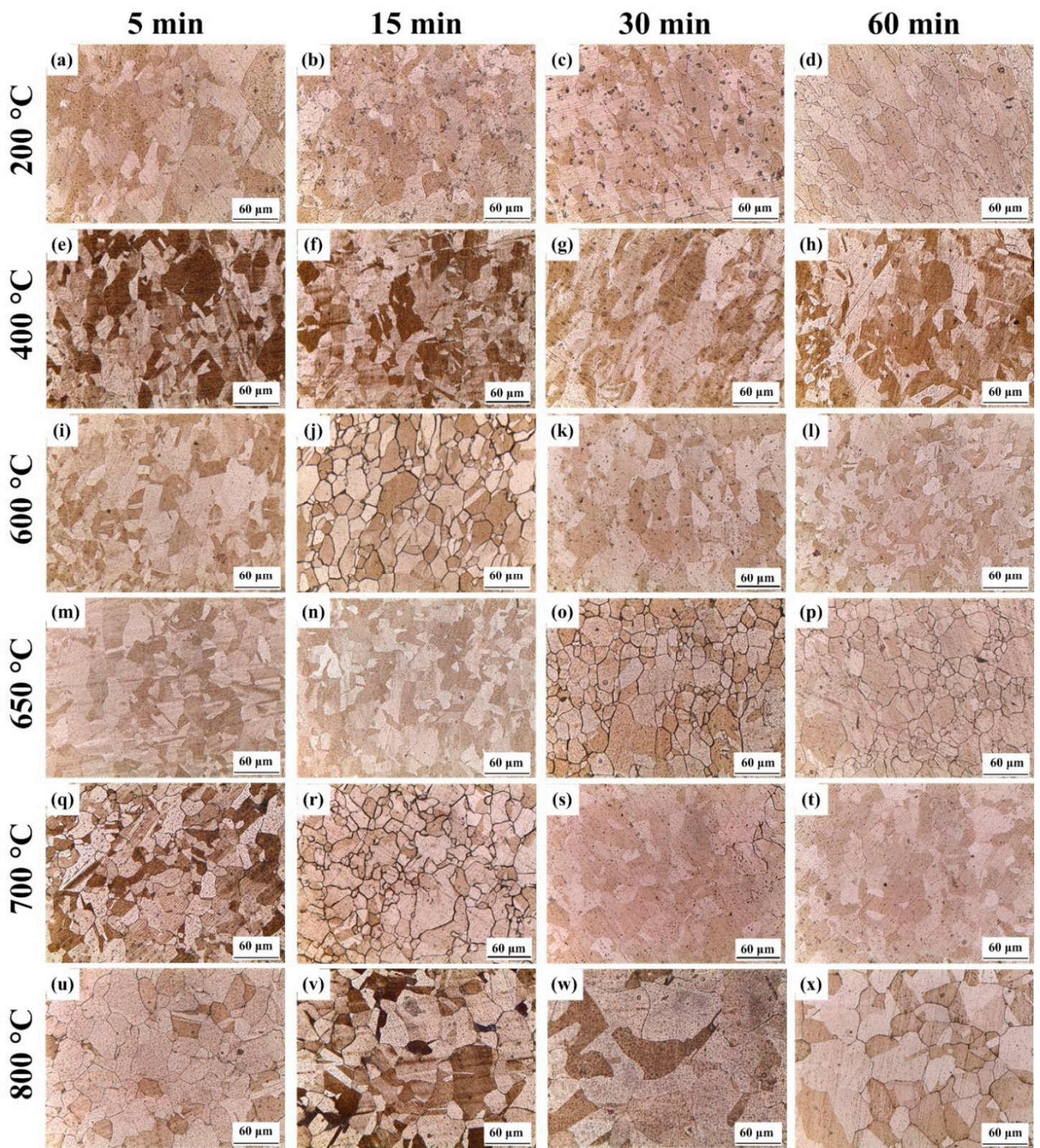

Figure 6. Microstructure of nickel sheets after pass 1 in Scheme 2 with subsequent annealing at different temperatures and time. 

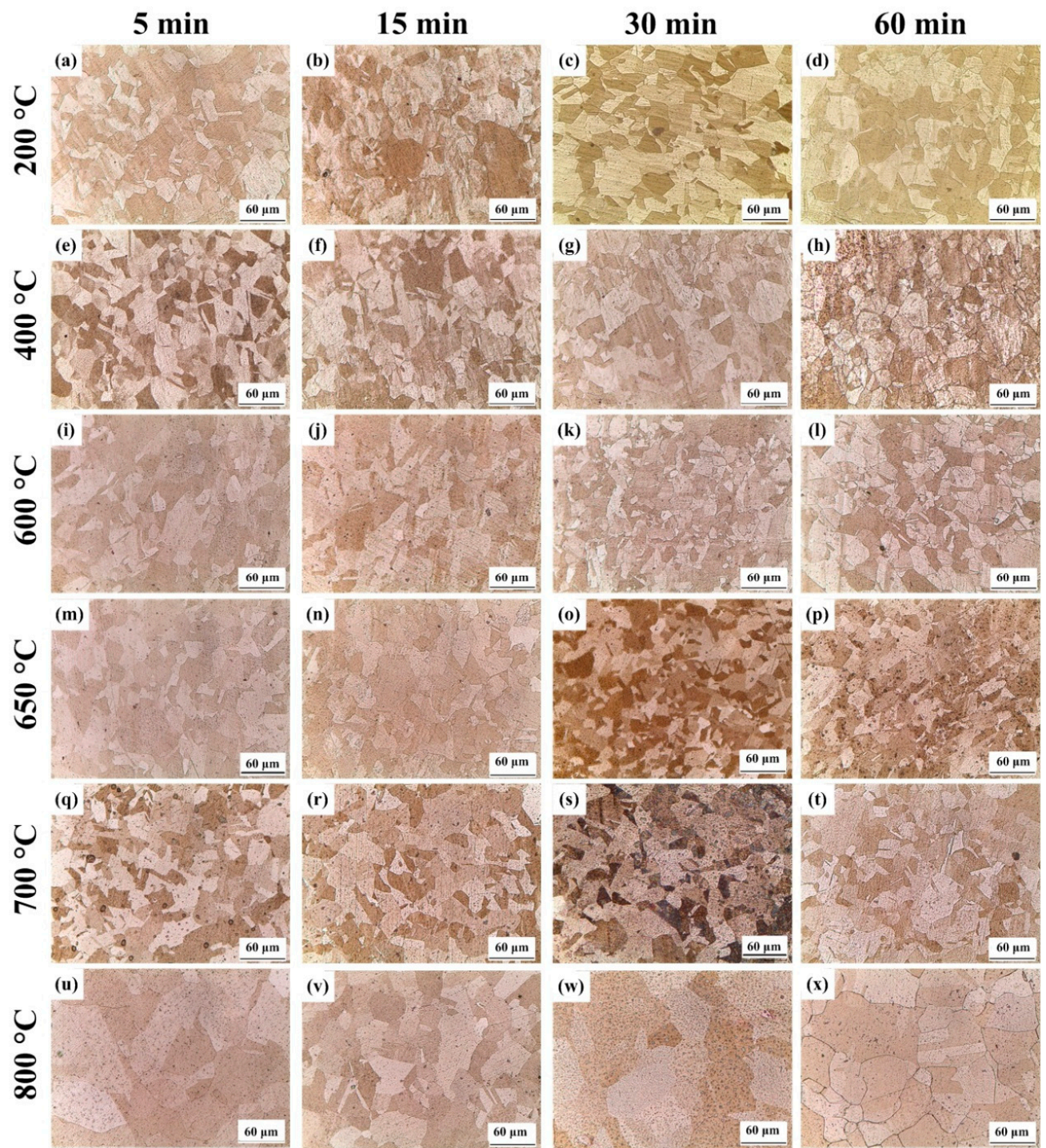

Figure 7. Microstructure of nickel sheets after pass 2 in Scheme 2 with subsequent annealing at different temperatures and time.

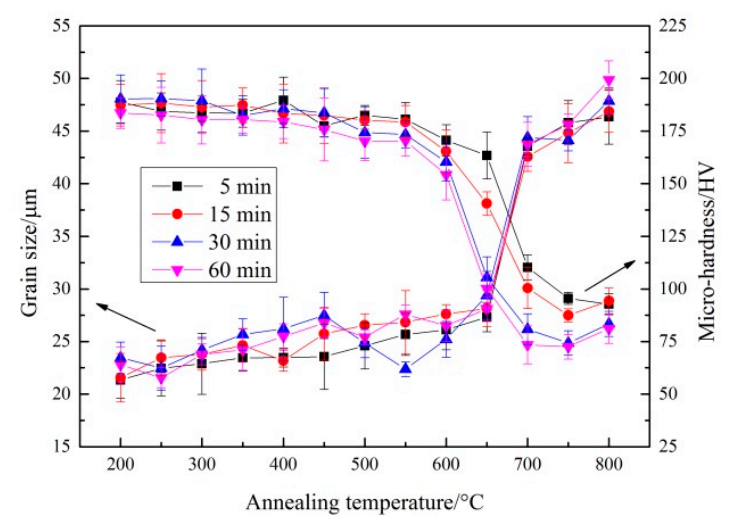

(a)

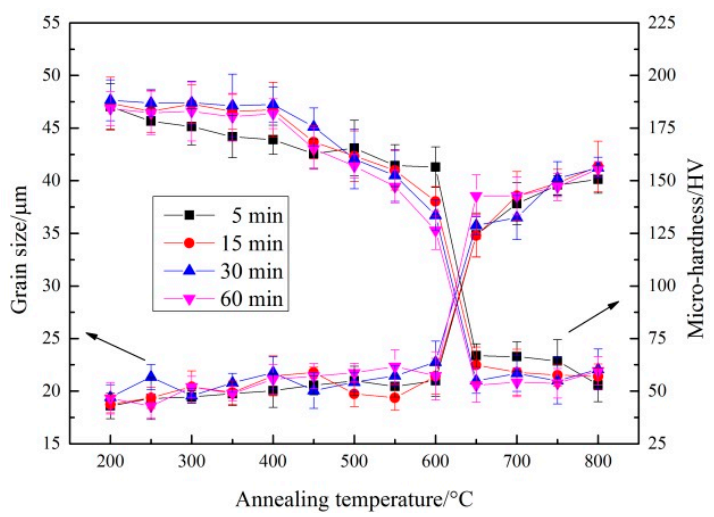

(b)

Figure 8. Variation of grain size and micro-hardness of CGP nickel sheets against annealing temperatures and time: (a) Pass 1; (b) pass 2. 


\subsection{Optimum Post-Deformation Annealing Procedure}

As discussed above, in this study, the optimum annealing temperature for CGP nickel sheets by one and two passes was determined as 650 and $600^{\circ} \mathrm{C}$, respectively, and it was believed to enhance the deteriorated ductility of SPD sheets by the heat treatment. Thus, for verification, RT tensile tests were conducted for the CGP sheets before and after post-deformation annealing for $1 \mathrm{~h}$, and the engineering stress-strain curves and corresponding tensile properties were given in Figures 9 and 10, respectively. Obviously, adequate annealing effectively improved the ductility without noticeable decrease in the strength of CGP nickel sheets at 650 and $600{ }^{\circ} \mathrm{C}$ for pass 1 and pass 2, respectively. For the sheets after pass 1, as shown in Figure 10a, the YS and UTS decreased from 458.5 and $499.1 \mathrm{MPa}$ to 315 and $457 \mathrm{MPa}$, respectively, while the elongation to failure increased remarkably from $10.6 \%$ to $27.3 \%$. Similarly for pass 2 , the elongation increased to $29.3 \%$ from the as-deformed $12.7 \%$, accompanied by slight drop of YS and UTS. From this point, annealing of severely deformed materials at a proper temperature before recrystallization started could restore their ductility with an acceptable decrease in the strength, especially the UTS, which must be an effective complementary approach for SPD methods [12].

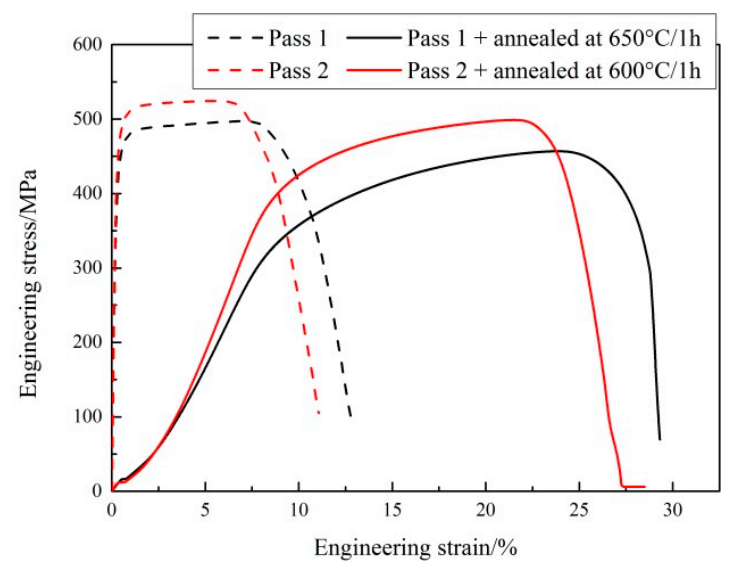

Figure 9. Engineering stress-strain curves of CGP nickel sheets before and after post-deformation annealing.

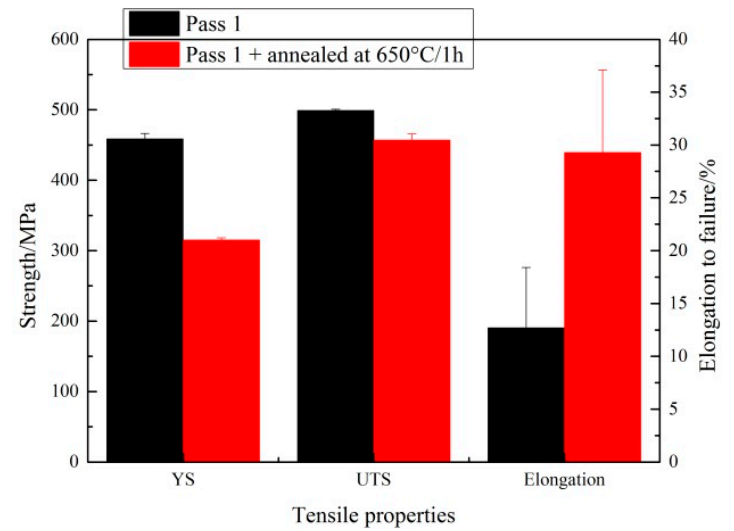

(a)

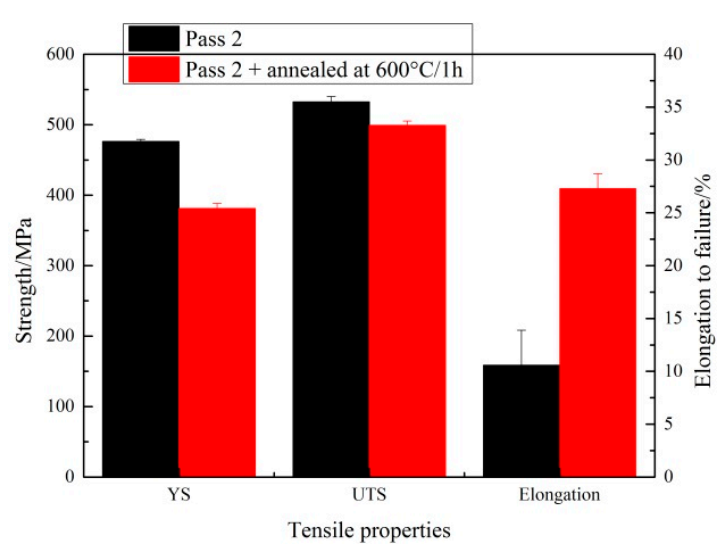

(b)

Figure 10. Tensile properties of CGP nickel sheets before and after post-deformation annealing: (a) Pass 1; (b) pass 2.

\section{Conclusions}

In this work, commercially pure nickel sheets were processed by CGP with different die designs, and the mechanical properties and fracture behavior were investigated. The thermal stability of the severely deformed materials was examined in detail, and the post-deformation annealing procedure 
to optimum mechanical properties of the sheets was obtained and verified. The main results can be presented as follows.

(1) Based on SEM observation of the fracture surface morphology of CGP nickel sheets, typical characteristics of fatigue fracture were confirmed, especially when the deformation mode transformed from pure shear to bending. The micro-crack initiation position and propagation direction were determined by inhomogeneous strain distribution and work hardening.

(2) The microstructure and mechanical properties of CGP nickel sheets by one and two passes exhibited good stability when heated at temperatures below 650 and $600{ }^{\circ} \mathrm{C}$, respectively, that is, higher accumulated plastic strain introduced lower thermal stability. This indicated that internal elastic stresses and accumulated energy increased with the CGP pass number, leading to higher driving force of recovery and recrystallization.

(3) In general, the effect of annealing temperature on CGP nickel sheets was more remarkable than annealing time while the effect of annealing time on variation of micro-hardness was more significant when heating materials deformed by one pass, especially at higher temperatures, during which annealing strengthening was clearly observed.

(4) RT tensile tests of CGP nickel sheets before and after optimum post-deformation annealing procedure demonstrated great recovery of ductility with an acceptable decrease in strength. The elongation to failure was increased to $27.3 \%$ and $29.3 \%$ from the as-deformed $10.6 \%$ and $12.7 \%$ by one and two passes, respectively.

Author Contributions: Conceptualization, Z.W.; Methodology, L.Z.; Investigation, L.L.; Writing—original draft preparation, Z.W.; Writing—review and editing, Y.G. and L.Z.; Supervision, Y.G.; Funding acquisition, Z.W.

Funding: This research was funded by National Natural Science Foundation of China, grant number 51605266.

Conflicts of Interest: The authors declare no conflict of interest.

\section{References}

1. Valiev, R.Z.; Estrin, Y.; Horita, Z.; Langdon, T.G.; Zehetbauer, M.J.; Zhu, Y. Producing Bulk Ultrafine-Grained Materials by Severe Plastic Deformation: Ten Years Later. JOM 2016, 68, 1216-1226. [CrossRef]

2. Valiev, R.Z.; Islamgaliev, R.K.; Alexandrov, I.V. Bulk nanostructured materials from severe plastic deformation. Prog. Mater. Sci. 2000, 45, 103-189. [CrossRef]

3. Shin, D.H.; Park, J.; Kim, Y.; Park, K. Constrained groove pressing and its application to grain refinement of aluminum. Mater. Sci. Eng. A 2002, 328, 98-103. [CrossRef]

4. Gupta, A.K.; Maddukuri, T.S.; Singh, S.K. Constrained groove pressing for sheet metal processing. Prog. Mater. Sci. 2016, 84, 403-462. [CrossRef]

5. Wang, Z.; Guan, Y.; Wang, T.; Zhang, Q.; Wei, X.; Fang, X.; Zhu, G.; Gao, S. Microstructure and mechanical properties of AZ31 magnesium alloy sheets processed by constrained groove pressing. Mater. Sci. Eng. A 2019, 745, 450-459. [CrossRef]

6. Fong, K.S.; Tan, M.J.; Ng, F.L.; Atsushi, D.; Chua, B.W. Microstructure Stability of a Fine-Grained AZ31 Magnesium Alloy Processed by Constrained Groove Pressing during Isothermal Annealing. J. Manuf. Sci. Eng. 2017, 139, 081007. [CrossRef]

7. Cao, W.Q.; Godfrey, A.; Liu, W.; Liu, Q. Annealing behavior of aluminium deformed by equal channel angular pressing. Mater. Lett. 2003, 57, 3767-3774. [CrossRef]

8. Jandaghi, M.R.; Pouraliakbar, H. Study on the effect of post-annealing on the microstructural evolutions and mechanical properties of rolled CGPed Aluminum-Manganese-Silicon alloy. Mater. Sci. Eng. A 2017, 679, 493-503. [CrossRef]

9. Pouraliakbar, H.; Firooz, S.; Jandaghi, M.R.; Khalaj, G.; Amirafshar, A. Combined effect of heat treatment and rolling on pre-strained and SPDed aluminum sheet. Mater. Sci. Eng. A 2014, 612, 371-379. [CrossRef]

10. Rafizadeh, E.; Mani, A.; Kazeminezhad, M. The effects of intermediate and post-annealing phenomena on the mechanical properties and microstructure of constrained groove pressed copper sheet. Mater. Sci. Eng. A 2009, 515, 162-168. [CrossRef] 
11. Khodabakhshi, F.; Kazeminezhad, M. The annealing phenomena and thermal stability of severely deformed steel sheet. Mater. Sci. Eng. A 2011, 528, 5212-5218. [CrossRef]

12. Pouraliakbar, H.; Jandaghi, M.R.; Khalaj, G. Constrained groove pressing and subsequent annealing of Al-Mn-Si alloy: Microstructure evolutions, crystallographic transformations, mechanical properties, electrical conductivity and corrosion resistance. Mater. Des. 2017, 124, 34-46. [CrossRef]

13. Pouraliakbar, H.; Jandaghi, M.R.; Heidarzadeh, A.; Jandaghi, M.M. Constrained groove pressing, cold-rolling, and post-deformation isothermal annealing: Consequences of their synergy on material behavior. Mater. Chem. Phys. 2018, 206, 85-93. [CrossRef]

14. Pouraliakbar, H.; Jandaghi, M.R. Mechanistic insight into the role of severe plastic deformation and post-deformation annealing in fracture behavior of Al-Mn-Si alloy. Mech. Mater. 2018, 122, 145-158. [CrossRef]

15. Popov, V.V.; Popova, E.N.; Kuznetsov, D.D.; Stolbovsky, A.V.; Shorohov, E.V.; Nasonov, P.A.; Gaan, K.A.; Reglitz, G.; Divinski, S.V.; Wilde, G. Evolution of Ni structure at dynamic channel-angular pressing. Mater. Sci. Eng. A 2013, 585, 281-291. [CrossRef]

16. Kumar, S.S.S.; Raghu, T. Tensile behaviour and strain hardening characteristics of constrained groove pressed nickel sheets. Mater. Des. 2011, 32, 4650-4657. [CrossRef]

17. Kumar, S.S.S.; Raghu, T. Mechanical behaviour and microstructural evolution of constrained groove pressed nickel sheets. J. Mater. Process. Technol. 2013, 213, 214-220. [CrossRef]

18. Wang, Z.; Guan, Y.; Wang, G.; Zhong, C. Influences of die structure on constrained groove pressing of commercially pure Ni sheets. J. Mater. Process. Technol. 2015, 215, 205-218. [CrossRef]

19. Wang, Z.; Guan, Y.; Liang, P. Deformation efficiency, homogeneity, and electrical resistivity of pure copper processed by constrained groove pressing. Rare Metals 2014, 33, 287-292. [CrossRef]

20. Wang, Z.; Liang, P.; Guan, Y.; Liu, Y.; Jiang, L. Experimental investigation of pure aluminum sheets processed by constrained groove pressing. Indian J. Eng. Mater. Sci. 2014, 21, 121-127.

21. Banerjee, A.; Gangadhara Prusty, B. Fatigue and fracture behaviour of austenitic-martensitic high carbon steel under high cycle fatigue: An experimental investigation. Mater. Sci. Eng. A 2019, 749, 79-88. [CrossRef]

22. Wang, Z.; Wang, T.; Guan, Y.; Wei, X.; Fang, X.; Zhu, G.; Gao, S. Effects of lubrication and strain path on constrained groove pressing of commercially pure aluminum sheets. Int. J. Adv. Manuf. Technol. 2019, 103, 511-527. [CrossRef]

23. Peng, K.; Mou, X.; Zeng, J.; Shaw, L.L.; Qian, K.W. Equivalent strain, microstructure and hardness of H62 brass deformed by constrained groove pressing. Comput. Mater. Sci. 2011, 50, 1526-1532. [CrossRef]

24. Peng, K.; Zhang, Y.; Shaw, L.L.; Qian, K.W. Microstructure dependence of a Cu-38Zn alloy on processing conditions of constrained groove pressing. Acta Mater. 2009, 57, 5543-5553. [CrossRef]

25. Yoon, S.C.; Krishnaiah, A.; Chakkingal, U.; Kim, H.S. Severe plastic deformation and strain localization in groove pressing. Comput. Mater. Sci. 2008, 43, 641. [CrossRef]

26. Jandaghi, M.R.; Pouraliakbar, H.; Khalaj, G.; Khalaj, M.; Heidarzadeh, A. Study on the post-rolling direction of severely plastic deformed Aluminum-Manganese-Silicon alloy. Arch. Civ. Mech. Eng. 2016, 16, 876-887. [CrossRef]

27. Popova, E.N.; Popov, V.V.; Romanov, E.P.; Pilyugin, V.P. Effect of the degree of deformation on the structure and thermal stability of nanocrystalline niobium produced by high-pressure torsion. Phys. Met. Metallogr. 2007, 103, 407-413. [CrossRef]

28. Ren, J.; Shan, A. Strengthening and stress drop of ultrafine grain aluminum after annealing. Trans. Nonferr. Metal. Soc. 2010, 20, 2139-2142. [CrossRef]

(C) 2019 by the authors. Licensee MDPI, Basel, Switzerland. This article is an open access article distributed under the terms and conditions of the Creative Commons Attribution (CC BY) license (http://creativecommons.org/licenses/by/4.0/). 